\title{
NATURALEZA JURÍDICA DE LA CIUDAD AUTÓNOMA DE MELILLA
}

\author{
POR \\ JUAN JOSÉ LÓPEZ RODRÍGUEZ
}

Doctor en Derecho 


\title{
NATURALEZA JURÍDICA DE LA CIUDAD AUTÓNOMA DE MELILLA
}

POR

\author{
JUAN JOSÉ LÓPEZ RODRÍGUEZ
}

\author{
Doctor en Derecho
}

En las siguientes páginas pretendemos realizar una breve reflexión, que aporte claridad, en torno a la naturaleza jurídica de la Ciudad Autónoma de Melilla y al pronunciamiento del Tribunal Constitucional, de 25 de julio de 2000, que concluyó que Melilla no constituye una Comunidad Autónoma, negándole la legitimación activa para recurrir ante el mismo.

La naturaleza jurídica de las Ciudades de Ceuta y Melilla es una cuestión compleja sobre la que la doctrina, que se había pronunciado antes del Auto del Tribunal Constitucional, de 25 de julio de 2000, se manifestaba: divergente ${ }^{1}$. Pero Melilla, al acceder a su régimen de autonomía a través de la Ley Orgánica $2 / 1995$, de 13 de marzo, no se configuró como una Comunidad Autónoma. Aunque presente determinados caracteres propios de éstas, no reúne todos los requisitos básicos señalados por el Tribunal

${ }^{1}$ Algunos autores consideraban que era un ente local especial dotado de un plus de autonomía (J.Tornos y E. Álvarez Conde). Otros entendian que se trataba de una Comunidad Autónoma (E. Alberti, P. Requejo, Castellá Andreu y Pons Parera), o bien mantenian que la naturaleza jurídica no se correspondía ni con la de los Municipios, ni con la de las Comunidades Autónomas (A.Torres del Moral, F. Balaguer, Cano Bueso, Montilla Martos y López Mira). 
Constitucional en sus Sentencias 76/1983, de 5 de agosto y 16/1984, de 6 de febrero, ni tampoco capacidad legislativa, elemento que el propioTC había utilizado anteriormente como criterio esencial para diferenciar la autonomía de las CCAA de la que es propia de los entes locales (STC 25/1981, de 14 de julio).

No obstante lo anterior, resulta obvio que desde la entrada en vigor del texto estatutario, Melilla ha accedido a un régimen de autonomía diferente del que tenía cuando sólo era un Municipio. La Ciudad de Melilla dispone de un ámbito competencial muy superior al de los Ayuntamientos; asimismo, tiene posibilidades de financiación que son propias de las CCAA; su Presidente es nombrado por el Rey; ostenta capacidad de iniciativa legislativa en los términos previstos en el art. 87.2 de la CE para las CCAA, que implica incluso la posibilidad de promover la reforma constitucional (art. $166 \mathrm{CE}$ ). Todo ello expresa un estatus impropio de los Municipios y de un alcance considerablemente superior al de los entes locales.

A mi parecer, no teniendo la naturaleza jurídica de las Comunidades Autónomas, ni tampoco la de un Municipio, la Ciudad de Melilla -como la de Ceuta - se configura como un ente territorial sui generis, dotado de una naturaleza jurídica mixta entre los tipos territoriales citados. Sin embargo, el Municipio no ha desaparecido, sino que ha quedado subsumido en el nuevo ente de carácter autonómico, evitándose, de esta manera, la duplicidad institucional. Así, vemos que no existen diferenciados la Asamblea y el Pleno Municipal, sino que aquélla tiene atribuidas las competencias de éste (art. 12.2 del Estatuto); el Presidente de la Ciudad ostenta también la condición de Alcalde y los miembros de la Asamblea son también Concejales (arts.15 y 7.2 del Estatuto). La preservación del Municipio ha sido confirmada por el Consejo de Estado, que ha señalado que sin entrar en la cuestión de si Melilla es o no una Comunidad Autónoma o constituye un ente autonómico específico, no cabe duda de que, en todo caso , es un Municipio².

Sin embargo, este peculiar estatus autonómico de las ciudades norteafricanas, ha dado lugar a patentes distorsiones. Así, cuando el Tribunal Constitucional, en su Sentencia 61/1997, de 20 de marzo, declaró la nulidad parcial de la Ley del Suelo señalando que el Estado no puede legislar sobre materias que sean competencias exclusivas de las Comunidades Autónomas basándose en la cláusula de supletoriedad del artículo 149,3, y

${ }^{2}$ Véase el dictamen del Consejo de Estado, de fecha 22 de junio de 2000. 
que, en consecuencia, carece de toda facultad para regular la materia, ni siquiera para derogar o modificar su propia legislación anterior, no tuvo en cuenta a las Ciudades Autónomas a las que estatutariamente se les habían asignado competencias en materia de urbanismo, pero, a diferencia de las CCAA, sin capacidad legislativa sobre las mismas para poder regular mediante ley estas competencias urbanísticas, sino sólo potestad reglamentaria en los términos previstos en la legislación general del Estado, por lo que no se trataba de una competencia exclusiva. Ello suponía que para ejercer su capacidad reglamentaria, Melilla y Ceuta deberían ajustarse a la obsoleta ley de Suelo de 1976, que había resucitado tras ser declarada parcialmente nula la regulación estatal posterior sobre la materia.

Esta distorsión, causada por la ausencia de capacidad legislativa de Melilla y Ceuta, podría enmendarse mediante la promulgación de una Ley estatal específica y actualizada, para que las Ciudades Autónomas actuaran dentro su marco y límite ejerciendo la facultad de que disponen para dictar reglamentos. Sin embargo, la Ley 6/1998, de 13 de abril, sobre Régimen del Suelo $y$ Valoraciones, era de aplicación a todo el territorio nacional y se limitaba a regular únicamente las condiciones básicas para garantizar la igualdad del ejercicio del derecho de propiedad del suelo, así como otras aspectos con incidencia en el urbanismo, tales como las expropiaciones, las valoraciones y los supuestos indemnizatorios, materias residuales sobre las que el Estado seguía conservando competencias. En la Disposición Adicional $3^{a}$ de la citada Ley se indicaba que "las Ciudades Autónomas de Ceuta y Melilla ejercerán las potestades normativas reglamentarias que tienen atribuidas por las Leyes Orgánicas 1/1995 y 2/1995, de 13 de marzo, dentro del marco de la presente Ley y de las que el Estado promulgue a tal efecton. El precepto no resolvía el problema suscitado, al referirse sólo a aspectos complementarios al urbanismo. Además, se facultaba expresamente a las Ciudades Autónomas a dictar reglamentos sobre una materia sometida a reserva de Ley ${ }^{3}$.

Posteriormente esta disposición sería modificada mediante la Ley 55/1999, que, en su articulo 68, atribuía al Ministerio de Fomento la competencia para la aprobación definitiva de los Planes Generales de. Ordenación Urbana. Ello suponía una evidente modificación, por medio de una Ley ordinaria, de las funciones asignadas a la Ciudad en materia de Urbanismo, señaladas en la Ley Orgánica de Estatuto de Autonomia (art. $\left.21.1^{\circ}\right)$ y precisadas en el Real Decreto de Traspaso, al amparo tanto del propio texto estatutario como de la Carta Magna (art. 148.1.3).

${ }^{3}$ Derecho de propiedad, artículo 33.3 CE. 
No hay que olvidar, asimismo, que el Tribunal Constitucional ha señalado, en su Sentencia 76/1983, de 5 de agosto, que la Ley estatal no puede imponerse a los acuerdos de las Comisiones Mixtas de Transferencias.

Por tal hecho, la Ciudad Autónoma procedió a solicitar al Defensor del Pueblo que interpusiera recurso de inconstitucionalidad, pero éste no ejerció su legitimación, argumentando que seguía el criterio de no intervenir en cuestiones que afectaran al orden competencial y cuando ya lo hubieran hecho las personas directamente afectadas, puesto que se deducía la voluntad de la Ciudad de Melilla de acudir directamente al Tribunal Constitucional ${ }^{4}$. El Defensor del Pueblo parecía considerar que la Ciudad de Melilla disponía de legitimación directa para recurrir ante el Tribunal Constitucional.

Más tarde el Ejecutivo autonómico melillense formuló recurso de inconstitucionalidad de forma directa ante el Tribunal Constitucional, al considerar que el citado artículo 68 de la Ley 55/1999 era inconstitucional, tanto desde el punto de vista material ${ }^{5}$, como desde el punto de vista formal ${ }^{6}$.

Pero el Tribunal Constitucional, en el Auto de 25 de julio de 2000, resolvió la inadmisiblidad del recurso deduciendo la falta de legitimidad de la Ciudad de Melilla por no constituir una Comunidad Autónoma. Sin embargo, el Alto Tribunal no se pronunció sobre la específica naturaleza jurídica de la Ciudad, por lo que aún no ha llegado a aclararse el encaje del nuevo ente territorial (Ciudad dotada de Estatuto de Autonomía) en la estructura territorial del Estado que, según contempla el artículo 137 de la Constitución, se organiza en Municipios, en Provincias y en las Comunidades Autónomas que se constituyan.

\footnotetext{
${ }^{4}$ Véase la Resolución del Defensor del Pueblo, en relación con el Expediente número $Q 0002031$.

${ }^{5}$ Por la posible infracción del orden de distribución de competencias recogido en el artículo $148.1 .3^{\circ}$ de la Constitución -que se refiere a la asunción de competencias en materia de ordenación del territorio, urbanismo $y$ vivienda $-y$ en los artículos $21.1 .1^{\circ} \mathrm{y}$ 21.2 del Estatuto - competencias de la Ciudad de Melilla en materia de ordenación del territorio, urbanismo y vivienda, y potestad normativa reglamentaria para desarrollar las citadas materias-.

${ }^{6}$ Por la supuesta vulneración del artículo 147.2.d de la Constitución -que se refiere al contenido del Estatuto en cuanto a las competencias asumidas y a las bases para el traspaso de los servicios correspondientes- y de la Disposición Transitoria Segunda del Estatuto- que regula el traspaso de los medios correspondientes a las competencias asumidas por la Ciudad.
} 
El máximo intérprete de la Constitución basó su resolución en que, durante la tramitación parlamentaria del Estatuto, la voluntad de las Cortes Generales no fue la de «autorizar" la constitución de Melilla como Comunidad Autónoma, evidenciándose tal hecho por el rechazo de aquellas enmiendas cuya finalidad era, precisamente, que Melilla se constituyera como Comunidad Autónoma (V. FJ 4). Consideraba el TC que la letra b) del artículo 144 contemplaba una doble posibilidad: que las Cortes Generales podían, por motivos de interés nacional, no solo "autorizar" la iniciativa para convertirse, en su caso, en Comunidad Autónoma (Disposición Transitoria Quinta, en relación con el inciso del artículo 144 b relativo a la "autorización" de las Cortes Generales), sino "acordar», sin la previa iniciativa de los Ayuntamientos, un Estatuto que otorgara un régimen de autonomía distinto del que gozan las Comunidades Autónomas (FJ 3), que en definitiva era el que se dispuso para las ciudades de Melilla y Ceuta.

Si bien es innegable que la voluntad de las Cortes al aprobar el Estatuto fue la declarada por el Alto Tribunal, éste no hizo mención alguna a la también palmaria voluntad constituyente puesta de manifiesto con la inclusión del término "autorizar" en el actual apartado b del artículo 144 de la Constitución y a la introducción de la Disposición Transitoria Quinta (vinculada al citado artículo 144) cuyo fin técnico, según indicaba la enmienda parlamentaria aprobada, era precisamente que los Estatutos de Ceuta y Melilla no puedan ser acordados, no puedan ser otorgados unilateralmente por las Cortes sin contar con ambas poblaciones ${ }^{7}$. Es decir, la voluntad constituyente fue que los Estatutos de Autonomía de las ciudades norteafricanas debían de ser autorizados por las Cortes Generales y no acordados unilateralmente por éstas, que fue lo que ocurrió, sin tener en cuenta, como ha señalado el propio TC, que la voluntad y racionalidad del poder constituyente, objetivadas en la Constitución, suponen un límite a la voluntad del legislador ${ }^{8}$.

Pero el Auto del Tribunal Constitucional, que negó la legitimación para interponer recurso de inconstitucionalidad a la Ciudad de Melilla ${ }^{9}$ evi-

${ }^{7}$ Véase BOCG . Congreso de los Diputados, núm. 121, de 1 de julio de 1978.

${ }^{8}$ STC 76/1983, de 5 de agosto, FJ 4.

${ }^{9}$ Al concluir que no era una Comunidad Autónoma, la falta de legitimación directa era clara ya que, como señalaba el propio TC en su resolución, los artículos 162.1 a) de la Constitución y el 32 de la Ley Orgánica del Tribunal Constitucional atribuyen dicha legitimación "los órganos colegiados ejecutivos de las Comunidades Autónomas y, en su caso, a las Asambleas de las mismas". 
denció otra patente distorsión: Melilla, tras la modificación operada en la LOTC por la ley 7/1999, en su condición de Municipio (subsumido en el ente autonómico que es la Ciudad), estaba legitimada para plantear ante el Tribunal Constitucional conflictos de competencias en defensa de la autonomía local ${ }^{10}$. Pero, sin embargo, como ente de rango autonómico y respecto de las competencias de tal carácter, atribuidas a través de la Ley Orgánica de Estatuto Autonomía , Melilla no puede formular recursos de inconstitucionalidad al no tener la condición de Comunidad Autónoma y no contemplarse la legitimación, ni en su Estatuto, ni en la LOTC. Ello implica la ausencia de mecanismos directos de defensa ante posibles intromisiones del Poder Central en las competencias de carácter autonómico que, por su rango y carácter, deberían de gozar de la protección adecuada.

Después de las cuestiones que se plantean en torno al nuevo ente territorial creado (Ciudades dotadas de Estatuto de Autonomía, que no constituyen Comunidades Autónomas) y sin perjuicio de que pueda considerarse positivo el acceso de las ciudades norteafricanas a su régimen de autonomía, éste debería ser el inicio de un camino que debe concluir en la reforma de los Estatutos, dotando a ambas Ciudades de los requisitos necesarios para que puedan ser encuadradas en la naturaleza jurídica de las CCAA $^{11}$, lo que evitaría estas $y$ otras distorsiones en un Estado Autonómico configurado sobre la base de Comunidades Autónomas, del que no pueden quedar descolgadas Ceuta y Melilla.

10 Esta legitimación como ente local fue confirmada por el Consejo de Estado (dictamen núm. 1.610/2000, de 22 de junio

11 La homogeneidad básica necesaria en las CCAA ha sido concretada por el TC en las sentencias 76/1983, de 5 de agosto, y 16/1984, de 6 de febrero. 